\title{
Infiltrating neutrophils promote renal cell carcinoma progression via VEGFa/HIF2a and estrogen receptor $\beta$ signals
}

\author{
Wenbin Song ${ }^{1,2, *}$, Chiuan-Ren Yeh ${ }^{1, *}$, Dalin $\mathrm{He}^{2, *}$, Yong Wang ${ }^{1}$, Hongjun Xie ${ }^{1,2}$, See- \\ Tong Pang ${ }^{1}$, Luke Sien-Shih Chang ${ }^{2}$, Lei $\mathbf{L i}^{2}$ and Shuyuan Yeh ${ }^{1}$ \\ ${ }^{1}$ George Whipple Lab for Cancer Research, Departments of Urology and Pathology, University of Rochester Medical Center, \\ Rochester, New York, USA \\ ${ }^{2}$ Sex Hormone Research Center, Department of Urology, The First Affiliated Hospital of Xi'an Jiaotong University, Xi'an, China \\ * These authors Contributed equally to this work \\ Correspondence to: Lei Li, email: lilydr@hotmail.com
}

Shuyuan Yeh, email: shuyuan_yeh@urmc.rochester.edu

Keywords: tumor microenvironment, RCC, Neutrophils, ERß, VEGFa and HIF pathways

Received: November 24, $2014 \quad$ Accepted: April 02, 2015

Published: June 15, 2015

This is an open-access article distributed under the terms of the Creative Commons Attribution License, which permits unrestricted use, distribution, and reproduction in any medium, provided the original author and source are credited.

\section{ABSTRACT}

Neutrophils make up a significant portion of the infiltrated immune cells found in the tumor microenvironment. Here we found more infiltrated neutrophils in human renal cell carcinoma (RCC) lesions than adjacent benign areas. In vitro RCC studies showed that neutrophils (HL-60N cells) infiltrated toward RCC cells and subsequently enhanced RCC cell migration and invasion. Co-culture of RCC cells with HL-60N cells up-regulated ER $\beta$, VEGFa and HIF2a mRNA levels. ER $\beta$ signals increased RCC cell migration via induction of the VEGFa/HIF2a pathway. Treatment of HIF inhibitor or rapamycin, or knockdown of ERB in RCC cells reversed HL-60N-promoted RCC migration. In vivo data using orthotopically xenografted RCC mouse model confirmed that infiltrated neutrophils promoted RCC migration via modulating the expressions of ERß, VEGFa and HIF2a signal pathways. Together, our studies revealed that neutrophils are favorably recruited to the RCC cells to promote the RCC migration and invasion. Targeting the infiltrating RCC tumor microenvironment with anti-estrogen or rapamycin may be a potential therapy to suppress RCC progression.

\section{INTRODUCTION}

Renal cell carcinoma (RCC) is a common urologic tumor and accounts for about $3 \%$ of all human malignancies with a steady increasing rate in recent decades [1]. The efficacy of therapy for RCC is limited as most RCC patients would soon develop resistance to conventional treatments including chemotherapy and radiotherapy [2].

$\mathrm{RCC}$ is considered to be an immunogenic tumor and a number of immunotherapeutic approaches have been exploited [3]. There is only partial or limited benefit obtained when selective RCC patients receive immunotherapies (high dose IL-2, IFN $\alpha+$ bevacizumab) or targeted therapies (tyrosine kinase inhibitors, mTOR inhibitors) [4]. The growth of RCC tumor cells is greatly influenced by the immune system [5]. RCC tissues exhibit a prominent infiltration of immune cells, consisting of $\mathrm{T}$ cells, natural killer (NK) cells, dendritic cells (DCs) and neutrophils. Despite profoundly infiltrated immune cells, RCC is not generally eliminated by different immune effector cells. Furthermore, immune dysfunction is found in some RCC patients, which likely contributes to tumor invasion [4]. It is of clinical interest to investigate how the tumor cells become resistant and escape from immune system control, and how the tumor associated immune cells influence the RCC development.

Evidences from epidemiological and pathological studies suggest that the neutrophil to lymphocyte ratio is an important prognostic factor based on a RCC study within a large European cohort [6]. Neutrophils are one type of the key tumor-infiltrating myeloid cells to influence tumor progression [7]. Similarly to the myeloid macrophages, neutrophils also contain a subpopulation of neutrophils named tumor-associated neutrophils (TAN) [8]. However, the potential relationship between TAN 
infiltration and human cancer prognosis has not been systematically discussed [9]. Epidemiological evidence has suggested that neutrophil infiltration within human cancers may be associated with a poor clinical outcome, as observed in patients with metastatic clear cell carcinomas and hepatocellular carcinoma [10].

In humans, estrogens play multiple important physiological roles. Estrogen exposure could lower the risk of heart attack, osteoporosis and breast cancer [11, 12]. But conversely, estrogen exposure could stimulate the growth of breast and uterine tissues. The bioeffects of estrogens are evident through their binding to estrogen receptors (ERs) and subsequent regulation of the transcription and activation of downstream genes. There are two major subtypes of ERs, ER alpha $(\mathrm{ER} \alpha)$ and $E R$ beta $(E R \beta)$. Distributions of $E R \alpha$ and $E R \beta$ vary in different tissue types [12, 13, 28, 38-40].

Our previous studies have shown that $\mathrm{ER} \alpha$ is barely detectable, yet ER $\beta$ is highly expressed and could promote proliferation and invasion in RCC both in vitro and in vivo. In the present study, results from RCC cell studies suggested co-culturing neutrophils with RCC cells could increase ER $\beta$ expression and its downstream signals. Additional new data showed that a positive correlation of increased ER $\beta$ levels and neutrophil infiltrations in the tumors at later stage of RCC tissues. Here, we studied the infiltrating neutrophils roles on the RCC progression with focuses on revealing functional mechanisms and how infiltrated neutrophils alter the ER $\alpha, \mathrm{VEGFa}$ and HIF $2 \alpha$ signals in the RCC.

\section{RESULTS}

\section{RCC has a better capacity than surrounding normal kidney tissues to recruit neutrophils}

To examine the potential impacts of neutrophils on RCC progression, we used IHC staining with neutrophils marker CD66b+ to compare neutrophil infiltration and results showed that more $\mathrm{CD} 66 \mathrm{~b}+$ neutrophils were recruited to the RCC lesions than in normal kidney tissues (Figure 1A).

We then applied the in vitro migration assay to confirm the above human clinical data. HL-60 cells were differentiated to neutrophil-like cells, HL-60N, by treating HL60 cells with $1.25 \%$ DMSO for 5 days. Tumor associated neutrophil markers, CD11b, MPO and hARG-1, were detected to validate the differentiation of neutrophils (HL-60N) (Figure 1B). To test whether RCC cells have a better capability than the non-malignant kidney cells to attract neutrophils, we applied a transwell Boyden chamber migration system. HL-60N cells were placed on the top wells, conditioned media (CM) from RCC or nonmalignant kidney cells were added in the bottom wells
(Figure 1C). After 8 hours of incubation, the number of HL-60N cells that migrated through the membranes were counted. Compared to the non-malignant kidney cells, HKC-2 or HKC-8, the RCC cells, 786-O and A498, have a much better capacity to recruit the HL-60N cells (Figure 1C).

Together, results from Figure 1A-1C suggest that RCC cells/tissues have a better capacity to recruit neutrophils than the surrounding normal kidney cells.

\section{Infiltrated neutrophils to RCC could enhance the RCC cell migration/invasion}

To further study the consequences of infiltrated neutrophils on RCC progression (Figure 2A), we then applied transwell plates to test the migration/invasion of RCC cells with or without co-culturing with neutrophils HL-60N cells for 7 days. RCC cells were then re-seeded in the upper transwell $\left(5 \times 10^{4} /\right.$ well $)$. The migration results showed the higher ability of migration in neutrophilco-cultured RCC cells than non-co-cultured RCC cells (Figure 2A). In addition, the transwell invasion assay results showed that co-culture of infiltrated HL-60N cells would allow RCC 786-O cells to gain a better invasion capacity (Figure $2 \mathrm{~B}, * P<0.05$ ). Similar results were obtained when we replaced RCC 786-O cells with the A498 cells, another RCC cell line.

\section{Mechanism studies: Infiltrated neutrophils could up-regulate ERß, VEGFa and HIF2 $\alpha$ signal pathways in RCC}

To further dissect the molecular mechanism(s) by which RCC cell invasion is enhanced after co-culture with neutrophil HL-60N cells, we applied Q-PCR-based focus-array analyses to search for the key metastasisrelated genes that are responsible for ER $\beta$-enhanced RCC progression. Among many increased metastasis-related genes, we found the expression of HIF $2 \alpha$ and vascular endothelial growth factor a (VEGFa) (VEGFa) and ER $\beta$ expressions were selectively increased in RCC 786-O and A498 cells after co-culture with neutrophils (Figure $3 \mathrm{~A})$. Western blot analysis results showed ER $\beta$ expression levels were different in various RCC cells (Figure 3B). Among these RCC cells, we choose 786-O cells that have high endogenous ER $\beta$ expression and A498 cells that have relatively low ER $\beta$ expression for further functional study. Figure $3 \mathrm{C}$ showed the increased HIF2 $\alpha$, VEGFa and ER $\beta$ protein expressions in both RCC cell after co-culture with HL-60N cells.

Together, results from Figures 2-3 using different RCC cell lines demonstrated that recruited neutrophils could enhance the RCC cell migration/invasion and infiltrated neutrophils may promote RCC cells invasion via up-regulation of ER $\beta$ signals in RCC cells. 
A

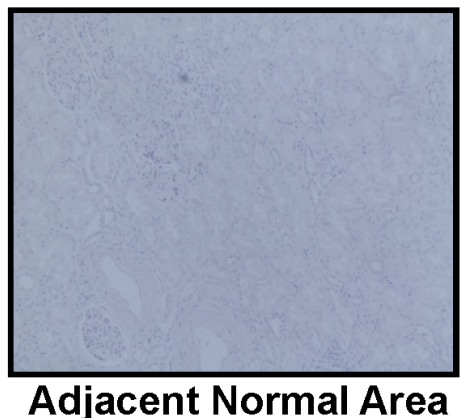

*

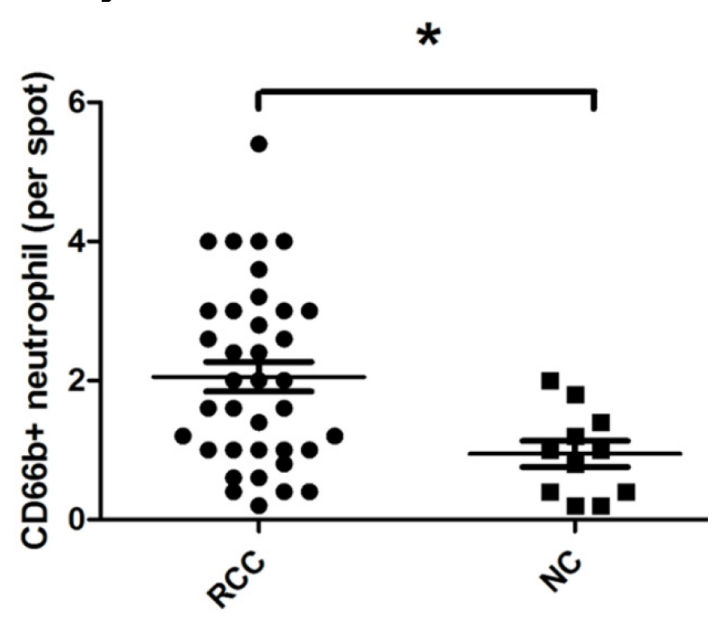

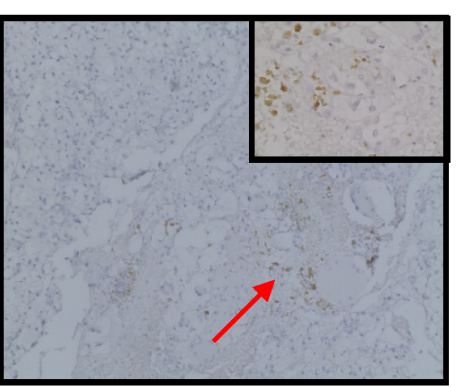

G1 RCC Area

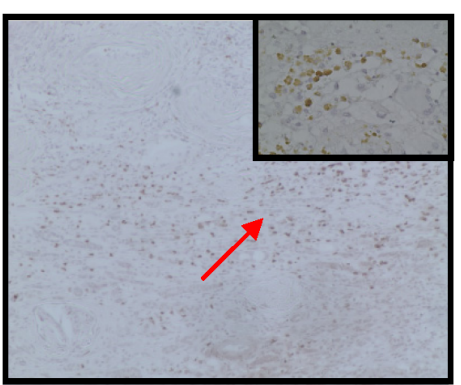

G3 RCC Area

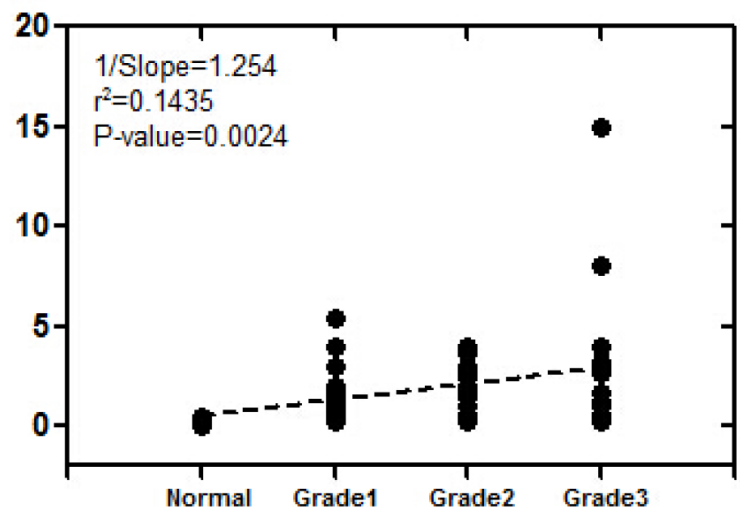

B
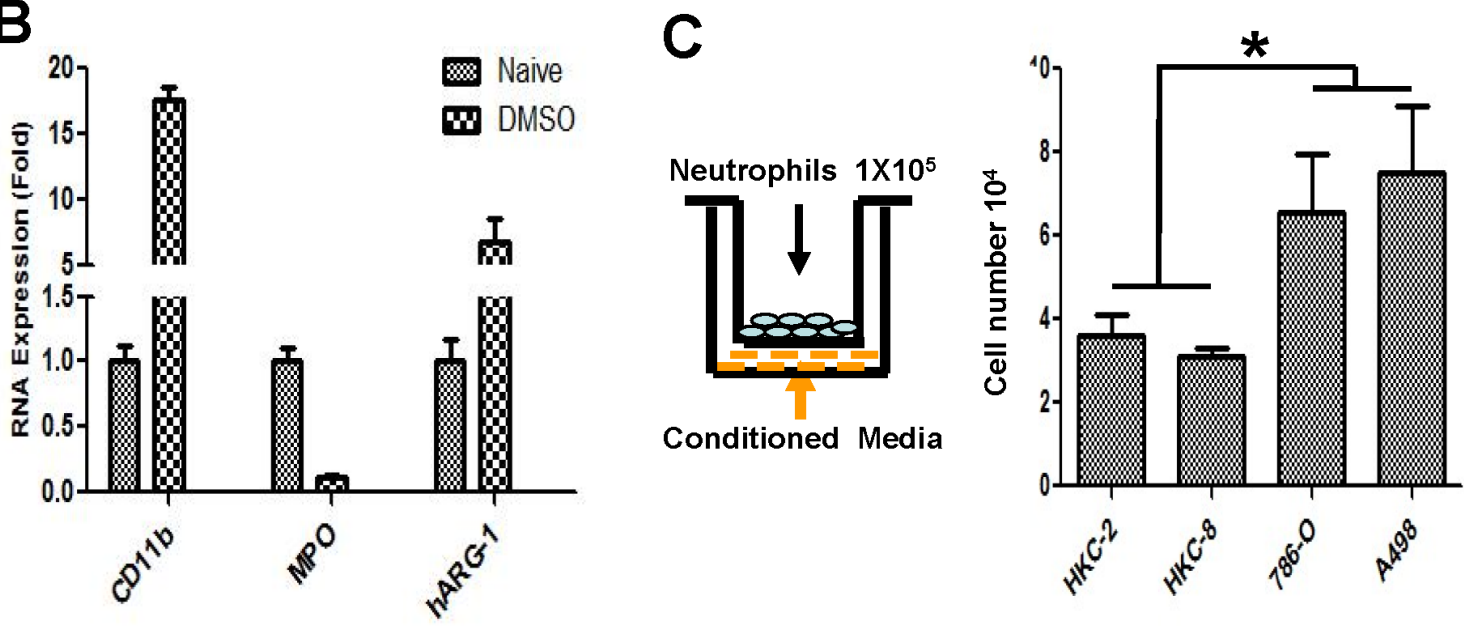

Figure 1: Compared to non-malignant kidney cells, RCC cells recruit more neutrophils. A. Human clear cell RCC specimens were stained for CD66b to detect neutrophils (upper panels). IHC staining results showed that more CD66b+ signals (red arrows), which suggested more neutrophil cells infiltrations, in the renal cancer area than in the adjacent normal kidney areas. To investigate the expression of CD66b in human RCC tissues, we collected malignant tissue specimens, along with 15 adjacent normal tissues, from 60 patients who had undergone partial or radical nephrectomy for primary RCC (lower panels). All tumor tissues were diagnosed according to the 2009 edition of the TNM system and nuclear grading was performed according to WHO guidelines. The clinic-pathological parameters of these tumors are listed in Table 1. B. After treating with 1.25\% DMSO for 5 days, HL-60 cells were differentiated to neutrophil-like cells, HL-60N. qPCR was applied to validate neutrophil marker (CD66b) and tumor associated neutrophil markers (CD11b, MPO, and hARG-1). C. RCC cells can better attract the HL-60N migration/infiltration. $1 \times 10^{5}$ of RCC cells or non-malignant kidney epithelial cells were plated into the lower chamber of the transwell. $1 \times 10^{5}$ of HL- $60 \mathrm{~N}$ cells were plated onto the upper chamber with $5 \mu \mathrm{m}$ pore polycarbonate membrane to determine HL-60N migration rate toward conditioned media (CM) collected from RCC or non-malignant kidney cells. After 8 hrs, the HL60-N cells migrated into the lower chamber were collected and counted by the Bio-Rad TC10 automatic cell counter. Compared to the normal kidney epithelial cell lines (HKC-2 and HKC-8), RCC cells (786-O and A498) recruited more HL-60N $(* P<0.05)$. 


\begin{tabular}{lc}
\hline \multicolumn{1}{c}{ Characteristics } & Informative cases \\
Median age (range), years & $56.4(29-71)$ \\
Sex & \\
Male & 39 \\
Female & 21 \\
Stage & \\
T1 & 37 \\
T2 & 14 \\
T3 & 9 \\
Grade & \\
G1 & 23 \\
G2 & 20 \\
G3 & 17 \\
Metastasis & \\
M0 & 49 \\
M1 & 11 \\
& \\
\hline
\end{tabular}

Table 1: Summery of the RCC tissues collected for the current study. RCC tissue specimens were collected from 60 clear cell RCC patients who had undergone partial or radical nephrectomy for primary RCC between 2002 and 2012. All tumor tissues were evaluated according to the 2009 edition of the TNM system and nuclear grading was performed according to WHO guidelines.

M0, tu mor without metastasis; M1, tu mor with metasta sis;

A
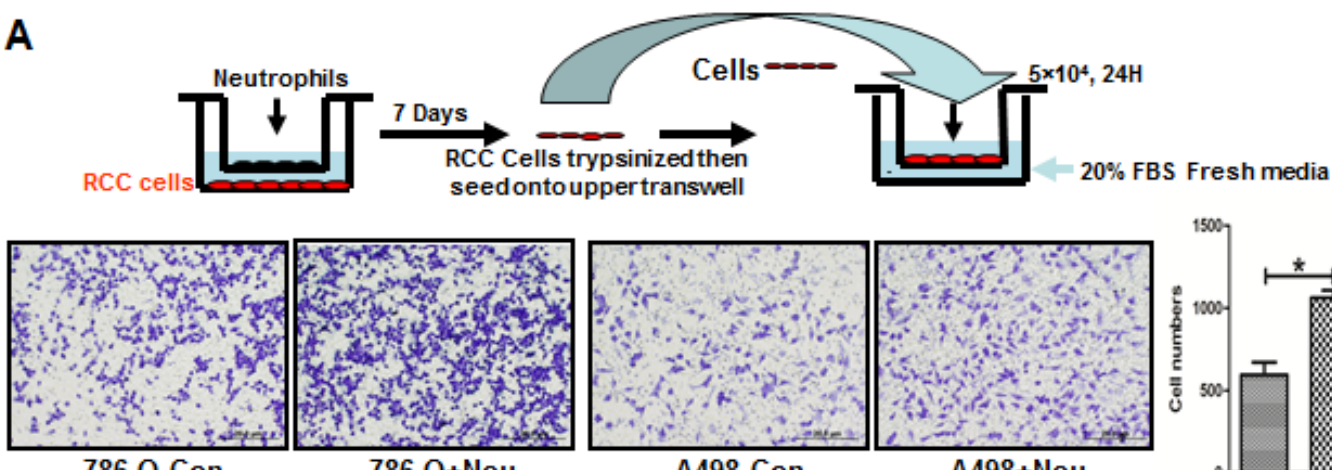

786-0 Con

786-O+Neu

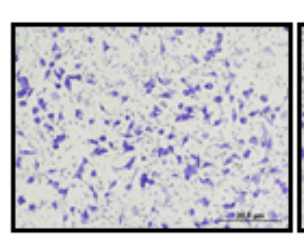

A498 Con
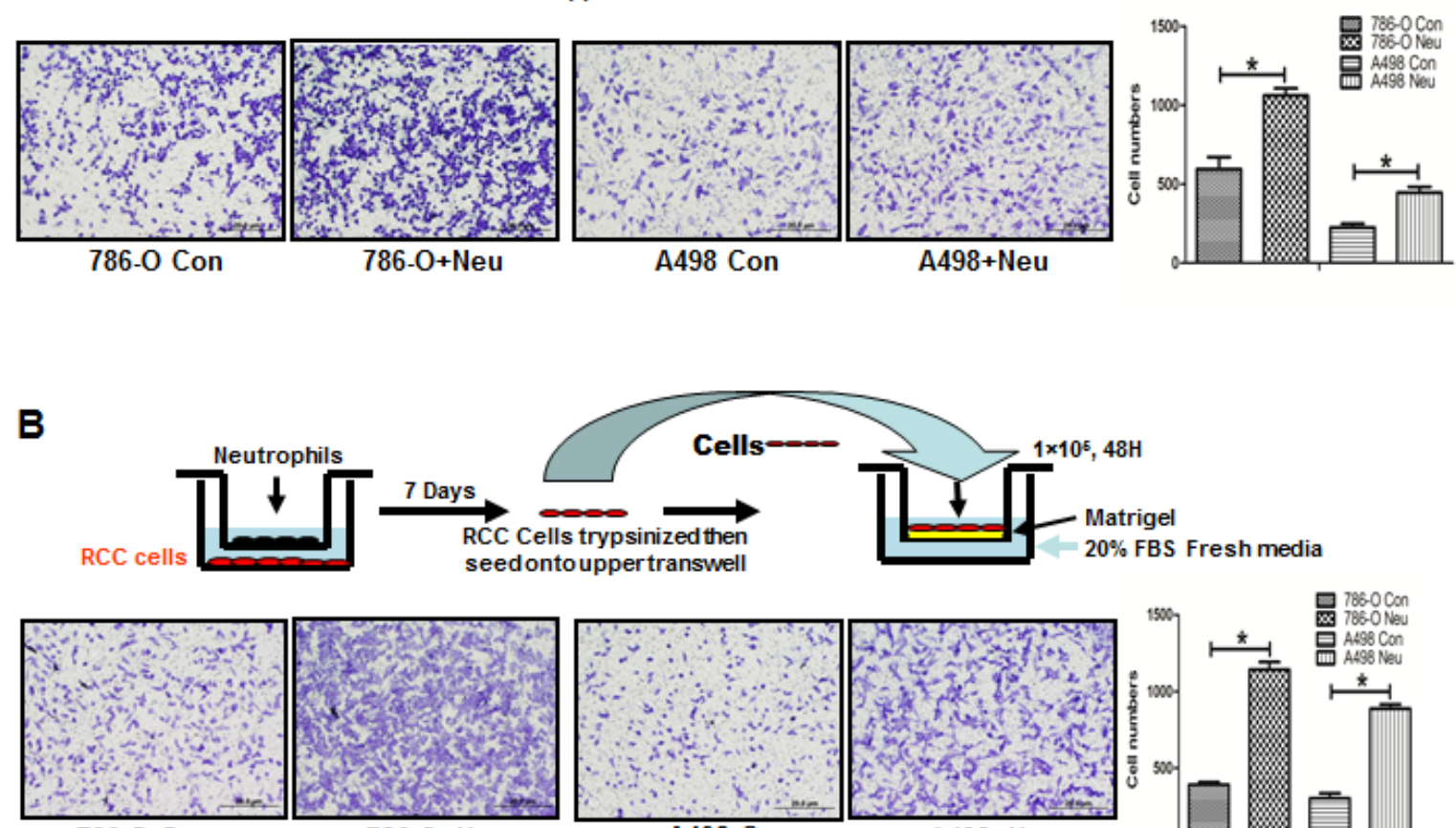

786-0 Con

786-O+Neu
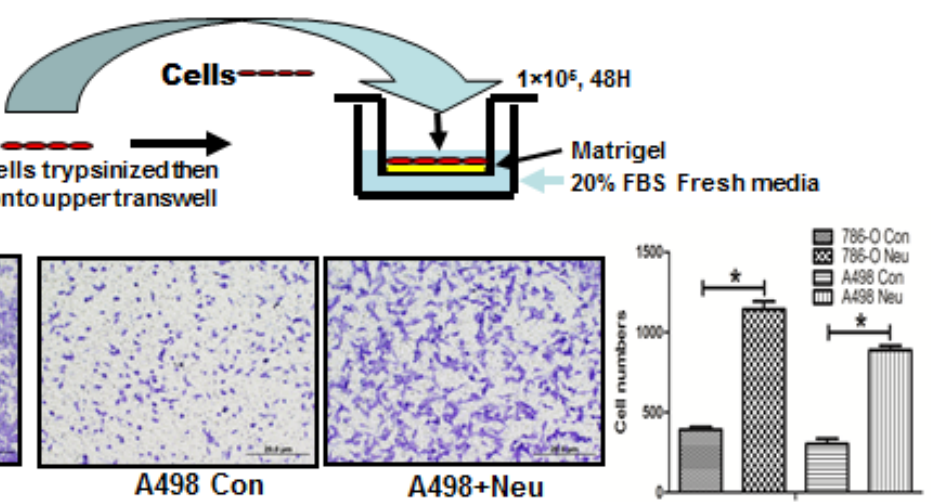

Figure 2: Co-culture with neutrophils promoted RCC invasion. A. The cartoon shows the procedure to co-culture RCC and HL$60 \mathrm{~N}$ cells and to test HL-60N cells promoted RCC migration. The RCC and HL-60N cells were co-cultured in $0.4 \mu \mathrm{m}$ pore size transwell plates for 7 days. After co-culturing with HL-60N, RCC cells were re-seeded into the upper chamber of a new transwell with $20 \%$ FBS fresh media in the bottom chamber. The transwell migration results showed that HL-60N co-cultured RCC cells have a higher migration capability $\left({ }^{*} P<0.05\right)$. B. HL-60N co-cultured RCC cells have a higher invasion capability. Using a protocol similar to A, we found that there was a higher invasion ability (through matrigel) in RCC cells after co-culture with HL-60N cells than non-co-cultured RCC cells. 
Knockdown of ERß, and treatment of HIF inhibitor or rapamycin can inhibit neutrophilspromoted RCC invasion

To validate the importance of ER $\beta$, VEGFa and
HIF $2 \alpha$ in neutrophils promoted RCC invasion, we used lentiviral-ER $\beta$ lentiviral-ER $\beta$ cDNA or shRNA transduced RCC cells. We first knocked down ER in 786-O cells that have high endogenous ER expression. RCC cells were then co-incubated with neutrophils for 7 days and seeded for invasion assay. Our data showed that knockdown of
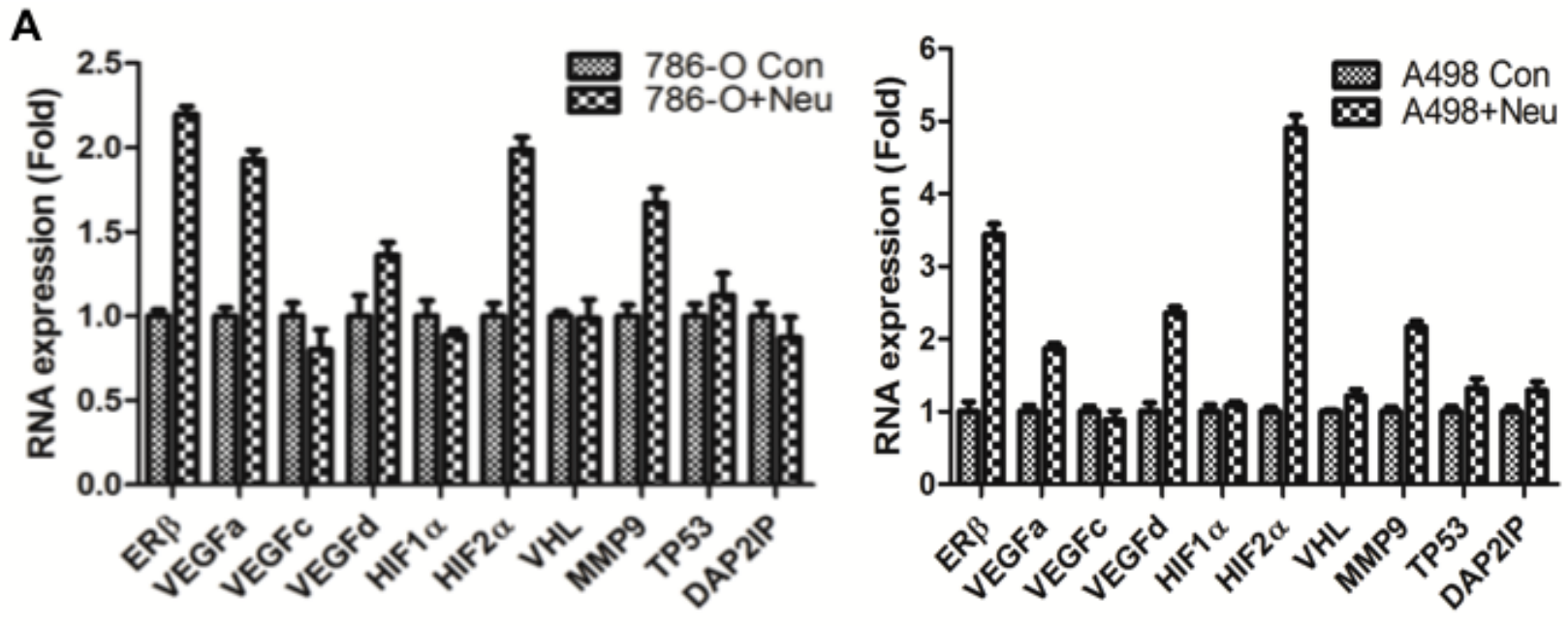

B
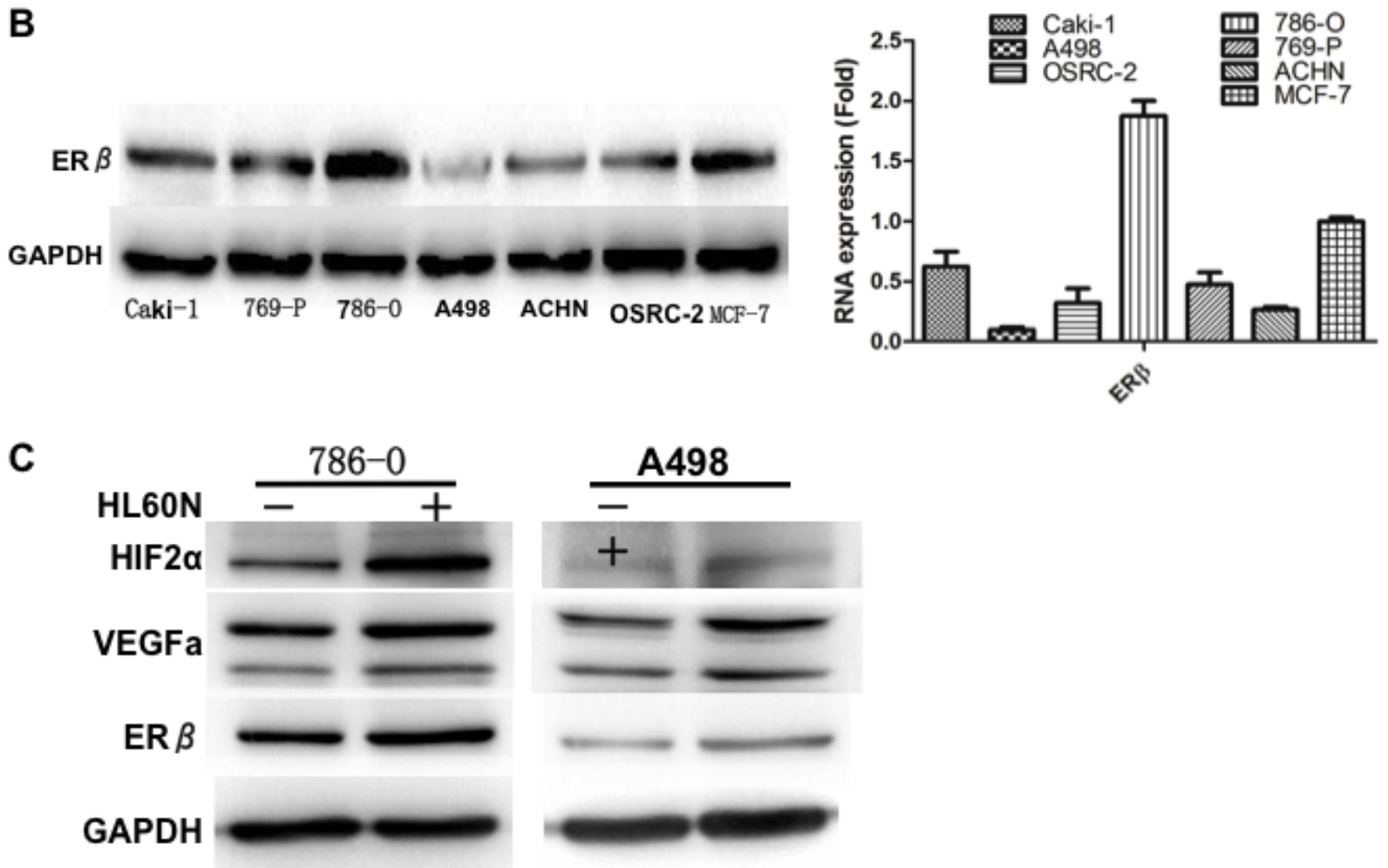

Figure 3: Mechanism dissection. A. Screening gene profile changes in neutrophil co-incubated RCC cells. Q-PCR results showed mRNA expressions of VEGFa and HIF2 $\alpha$, but not VEGFc, VEGFd and HIF1 $\alpha$, were selectively and significantly increased in RCC cells after co-culture with HL-60N cells for 7 days. The data were validated in 2 different RCC cell, 786-O and A498. B. Detection of ER $\beta$ levels in different RCC cells. Western blot detection of ER $\beta$ in different RCC cell lines. Breast cancer cells, MCF-7, were used as a positive control for ER $\beta$ expression. ER $\beta$ has the highest expression level in 786-O and the lowest in A498 cells. qPCR was applied to check ER $\beta$ expression in RCC cell lines. C. Western blot detection of ER $\beta$, VEGFa and HIF2a protein expressions after co-culture with HL-60N cells. Data showed that co-culture of HL-60N and RCC cells could increase ER $\beta$ and other invasion/angiogenesis related genes in RCC cells. GAPDH was used as control to show the equal loading of protein. 
A

$786-0$
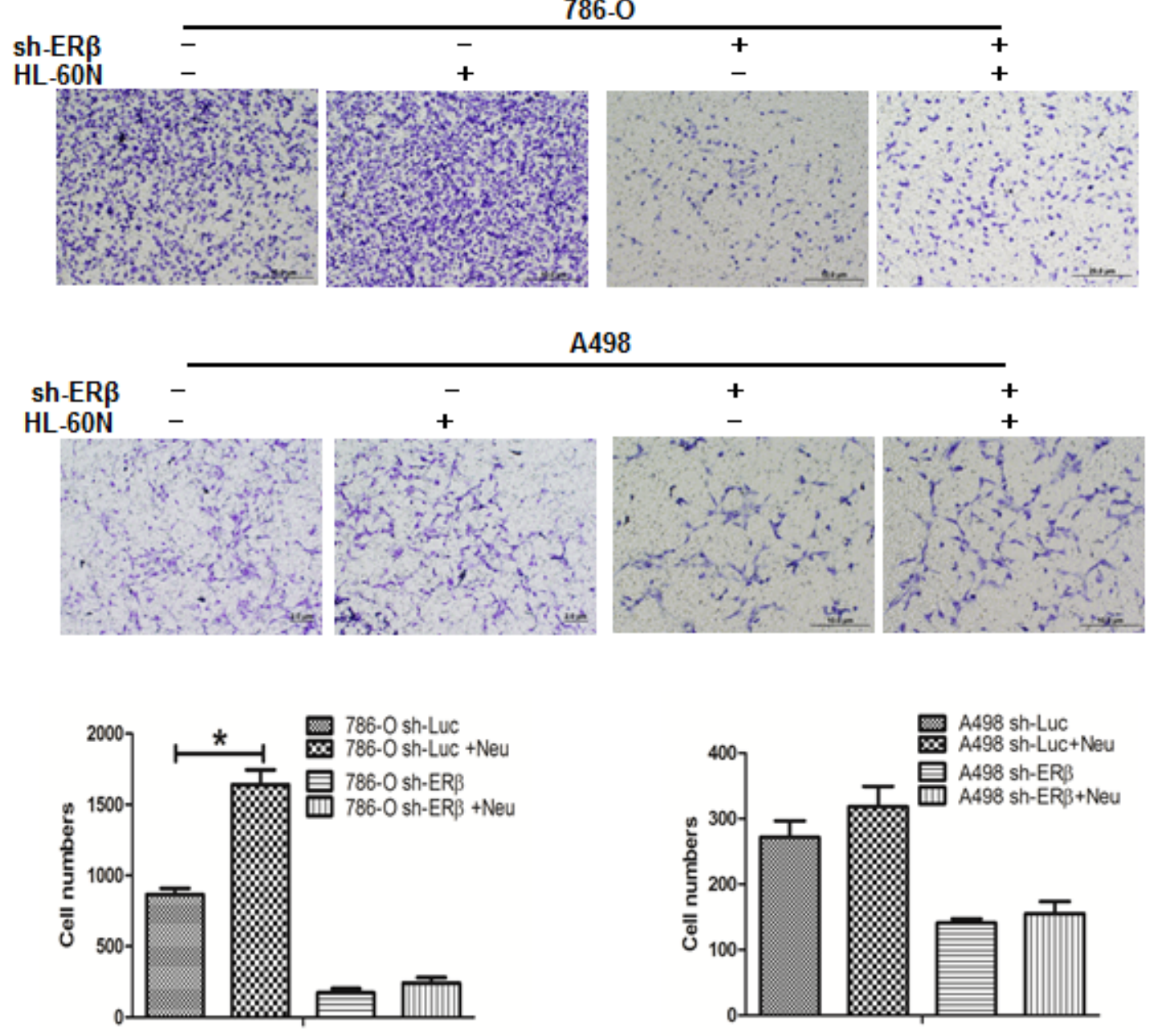

B

$786-0$
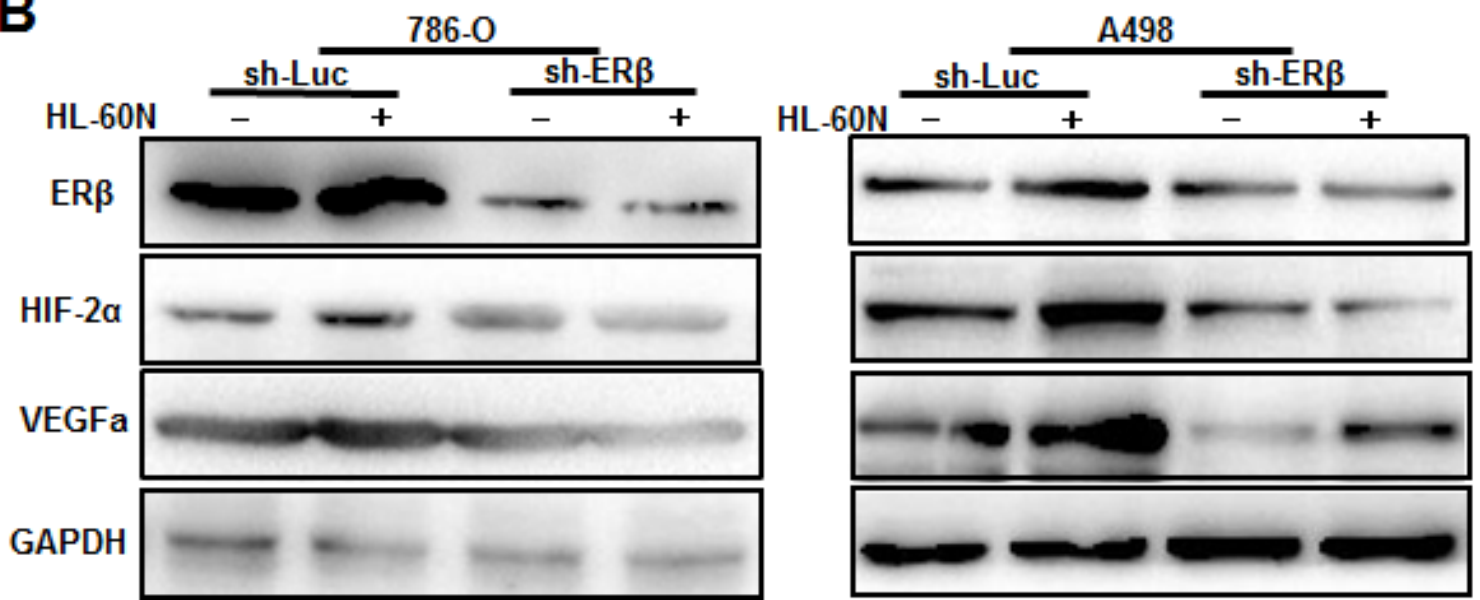

Figure 4: Down-regulated ER $\beta$ could regulate the down-stream VEGFa and HIF2 $\alpha$ pathways in RCC cells. A. We used the lentiviral-shRNA system to knock down ER $\beta$ in 786-O (with high endogenous ER $\beta$ ) and A498 (with low endogenous ER $\beta$ ), then co-cultured with HL-60N for 7 days. Data showed that knockdown of ER $\beta$ expression can reverse HL-60N promoted RCC invasion. B. Western blot data showed that ER $\beta$, VEGFa and HIF2 $\alpha$ protein increases in RCC cells after co-culture with HL-60N cells. Knockdown of ER $\beta$ in RCC could diminish the HL-60N co-culture promoted VEGFa and HIF2 $\alpha$ expressions in RCC cells. 
$\mathrm{ER} \beta$ in RCC cells could inhibit neutrophils-promoted RCC invasion. Interestingly and importantly, when we knocked down ER $\beta$, we observed a reduced expression of the VEGFa and HIF $2 \alpha$ in HL-60N co-cultured RCC cells (Figure 4). Furthermore, an interruption approach using HIF inhibitor can effectively reverse neutrophil-coculture induced HIF2a expression and invasion in RCC cells (Figure 5A and 5B).

In addition to knocking down ER $\beta$ and treatment with HIF inhibitor, we also examined the effects of rapamycin, which was reported to inhibit the migration of neutrophils [14], or macrophages [15]. Also, Rapamycin has the potential to be used as treatment of different types of cancers $[16,17]$. We tested whether rapamycin could interrupt the infiltration of neutrophils toward RCC cells as well as the neutrophils-enhanced RCC invasion. Results showed that rapamycin treatment could effectively inhibit the capability for neutrophils to infiltrate through coated transwell-membrane (Figure 5C) and consequently inhibit the neutrophils-enhanced RCC invasion (Figure 5D).

Together, results from Figures 4 and 5 suggest that infiltrated neutrophils may function through modulation

A

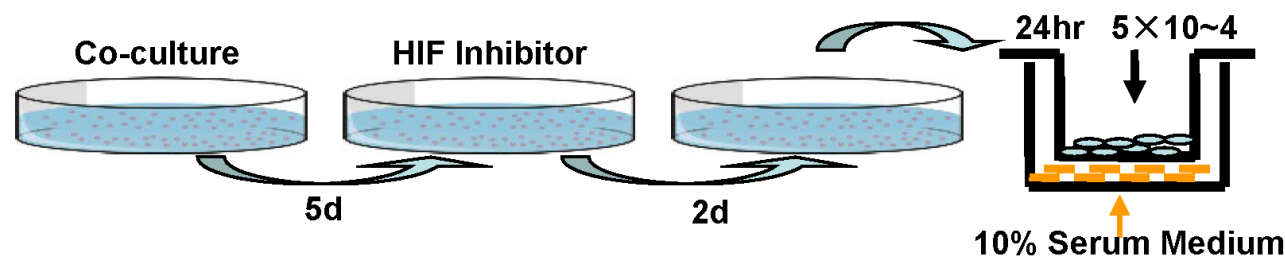

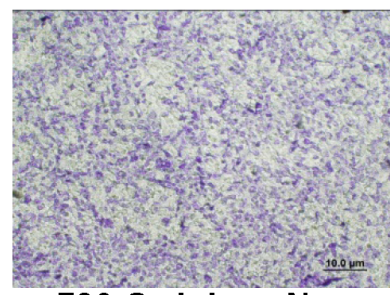

786-O sh-Luc+Neu

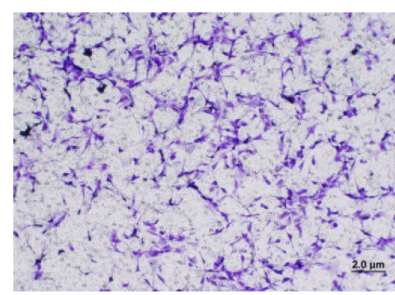

A498 sh-Luc+Neu

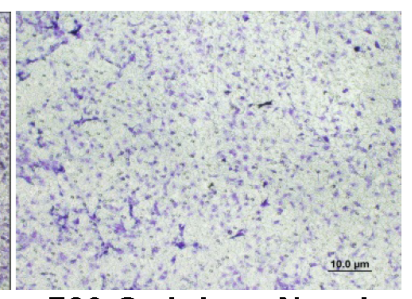

786-O sh-Luc+Neu+In

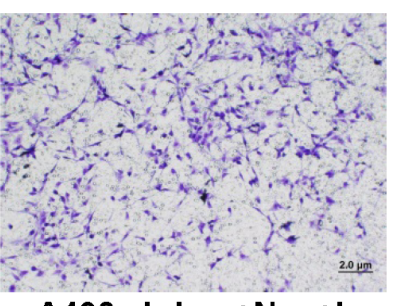

A498 sh-Luc+Neu+In

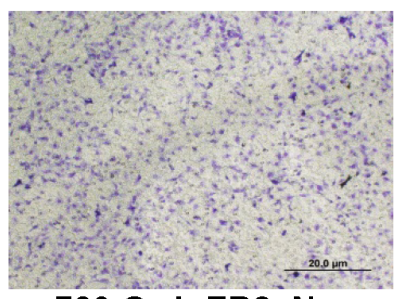

786-O sh-ER $\beta+\mathrm{Neu}$

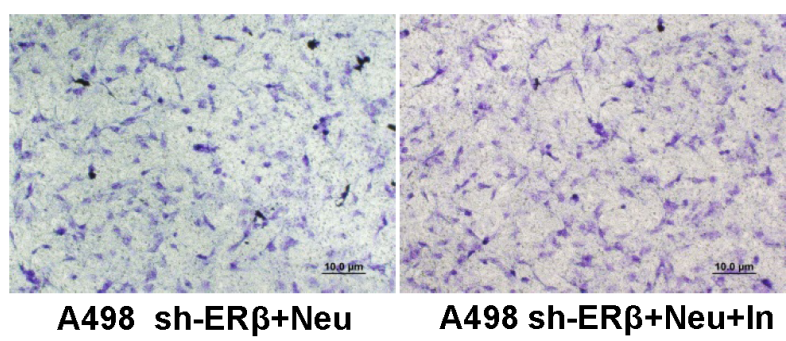

B

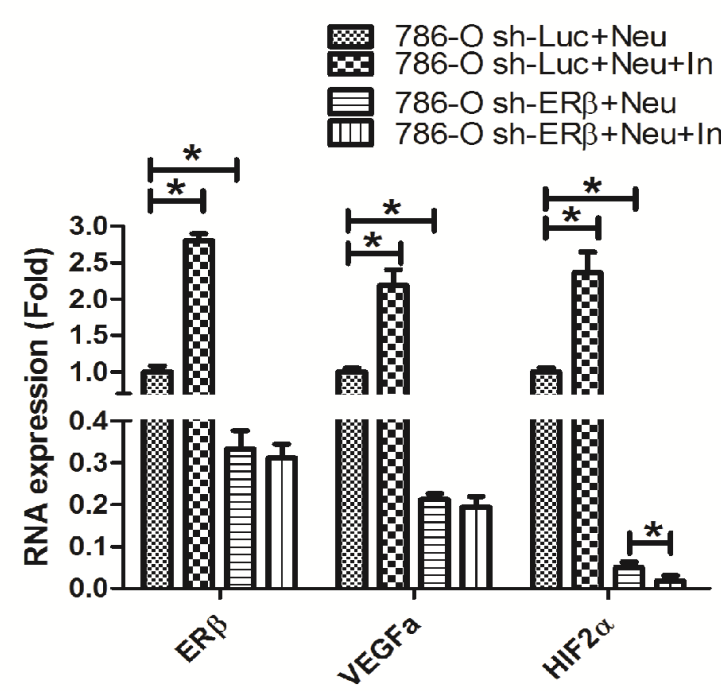

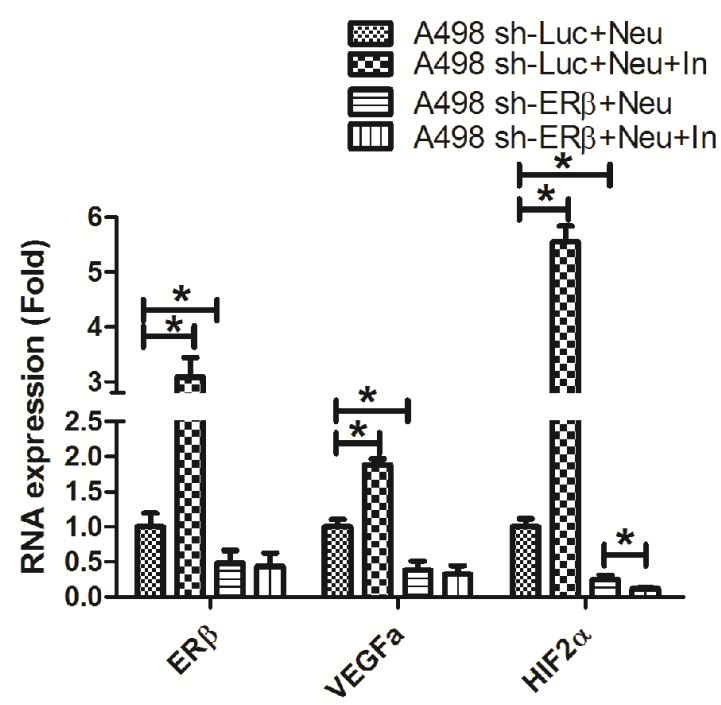




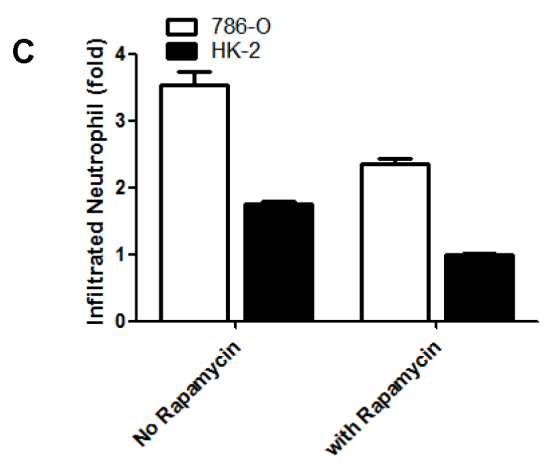

D
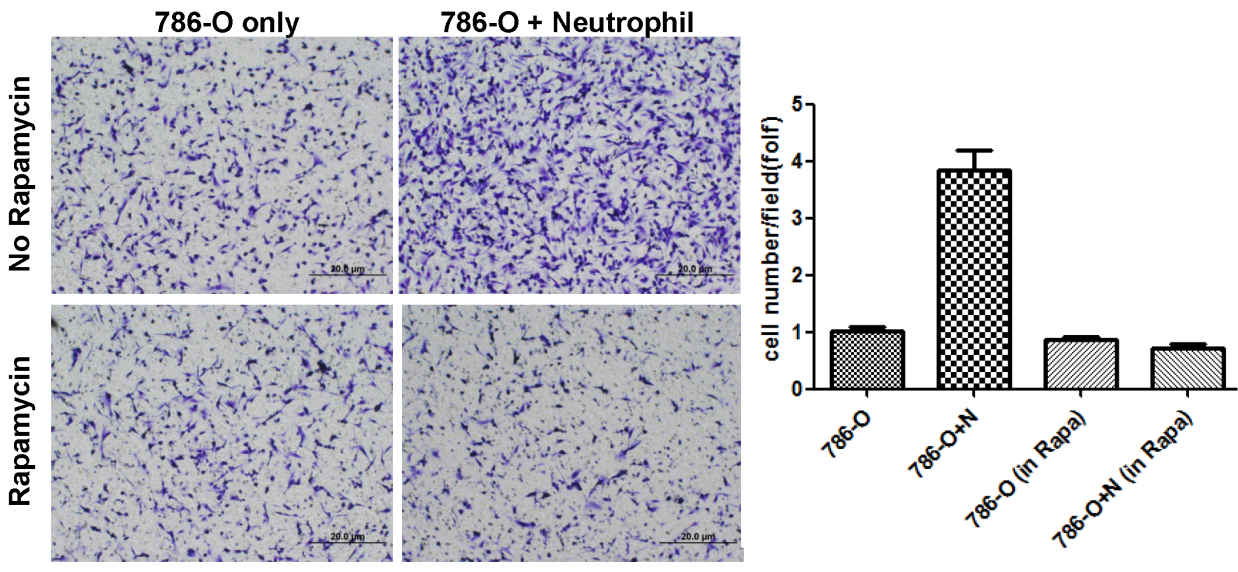

Figure 5: HIF inhibitor and rapamycin treatment can attenuate neutrophils-promoted RCC migration and invasion. A. Using lentiviral system to knockdown ER $\beta$ in A498 and 786-O, those RCC cells were then co-cultured with HL-60N. After 5 days co-culture, $10 \mu \mathrm{M}$ HIF inhibitor was added for 2 more days. RCC cells were then trypsinized and seeded in the upper chambers of transwells $\left(5 \times 10^{4} /\right.$ well $)$ with $10 \%$ FBS media for $24 \mathrm{hr}$ to determine the migration rate. The cartoon illustrates the procedure to perform the experiments. B. qPCR to detect ER $\beta$, VEGFa and HIF2 $\alpha$ expression with or without treatment of HIF inhibitor. Together, our data support that a lower ER $\beta$ expression can down-regulate VEGFa/HIF2 $\alpha$ expression. HIF inhibitor treatment can diminish neutrophils/ ER $\beta$-stimulated RCC migration. C. Rapamycin treatment suppresses neutrophil infiltration. CMs collected from 786-O and HK2 cells with/without rapamycin $(10 \mathrm{ng} / \mathrm{ml})$ treatment were put in bottom wells of 24 wells cell culture plate. Neutrophils were seeded into uppertranswell (pore size: $5 \mu \mathrm{m}$ ). Infiltrated neutrophils were collected in bottom wells after 3 hrs of incubation. D. Rapamycin treatment could attenuate neutrophil-promoted RCC invasion. In the upper left panel: 786-O alone with DMSO mock treatment; the upper right panel: HL$60 \mathrm{~N}$ co-cultured with 786-O cells with DMSO mock treatment. In the bottom left panel, 786-O cells with rapamycin treatment; in bottom right panel, HL-60N and 786-O co-culture with rapamycin treatment $(10 \mathrm{ng} / \mathrm{ml})$. RCC invasion quantification results were averaged from counting six representative fields under microscope of each condition. Results were normalized to 786-O only with DMSO treatment.

of $\mathrm{ER} \beta / \mathrm{VEGFa} / \mathrm{HIF} 2 \alpha$ signals to enhance the RCC cell invasion. The inhibition of neutrophils by rapamycin, or by blocking ER $\beta$ and HIF2 $\alpha$ may be applied as alternative therapy strategies to control RCC invasion.

\section{Infiltrated neutrophils enhanced RCC invasion in the in vivo mouse model}

To confirm the above in vitro RCC cell study results in the in vivo pre-clinical RCC model, we then orthotopically implanted RCC 786-O and/or HL-60N cells (9:1 ratio) under the renal capsule to test the tumor growth and metastasis.
RCC 786-O cells were first stably transfected with luciferase and IVIS imaging was applied to monitor RCC tumor growth and metastasis 3 weeks after tumor implantation, followed by weekly IVIS detection for an additional 5 weeks. Eight weeks after tumor implantation, the mice were sacrificed for tumor characterization. Results consistently showed that tumors were bigger in the mice co-implanted with 786-O cells and HL-60N cells (Figure 6A). Representative IVIS images were shown on the left panel of Figure 6B. Metastases were found in the diaphragm of neutrophils co-implanted RCC tumors. There are higher metastatic rates in $786-\mathrm{O}+\mathrm{HL}-60 \mathrm{~N}$ coimplanted mouse tumor group $(9 / 10,90 \%)$ as compared to $786-\mathrm{O}$ cell only group $(4 / 10,40 \%)$ (Figure $6 \mathrm{~B})$. In 
addition, IHC staining of mouse RCC tumors showed the expressions of ER $\beta$, VEGFa, and HIF2 $\alpha$ markers were consistently higher in 786-O+HL-60N tumor group than 786-O tumor group (Figure 6C).

Together, results from in vivo mouse model studies (Figure 6A-6C) confirmed the above in vitro cell lines studies (Figures 3 and 4) and demonstrated that infiltrated neutrophils could enhance RCC growth and invasion via modulating ER $\beta$ and VEGFa/HIF $2 \alpha$ signals.

\section{DISCUSSION}

Besides tumor cells, the tumor microenvironment is composed of a wide spectrum of immune cell types, which can significantly affect cancer progression and patient outcome. Tumor-infiltrating neutrophils (TIN) are known to make up a significant part of the immune cells within the tumor microenvironment in different types of human cancer [18-20]. Despite their origin in the peripheral blood, TINs have been shown to exhibit impaired bactericidal and enhanced angiogenic activities [21]. The presence of intra-tumoral neutrophils has been reported

A
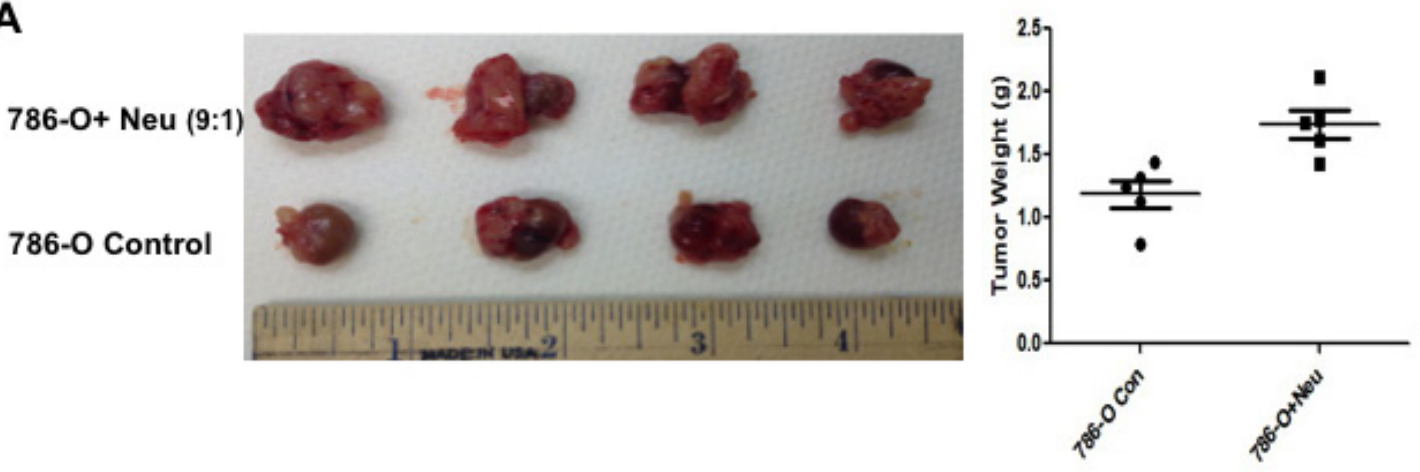

B
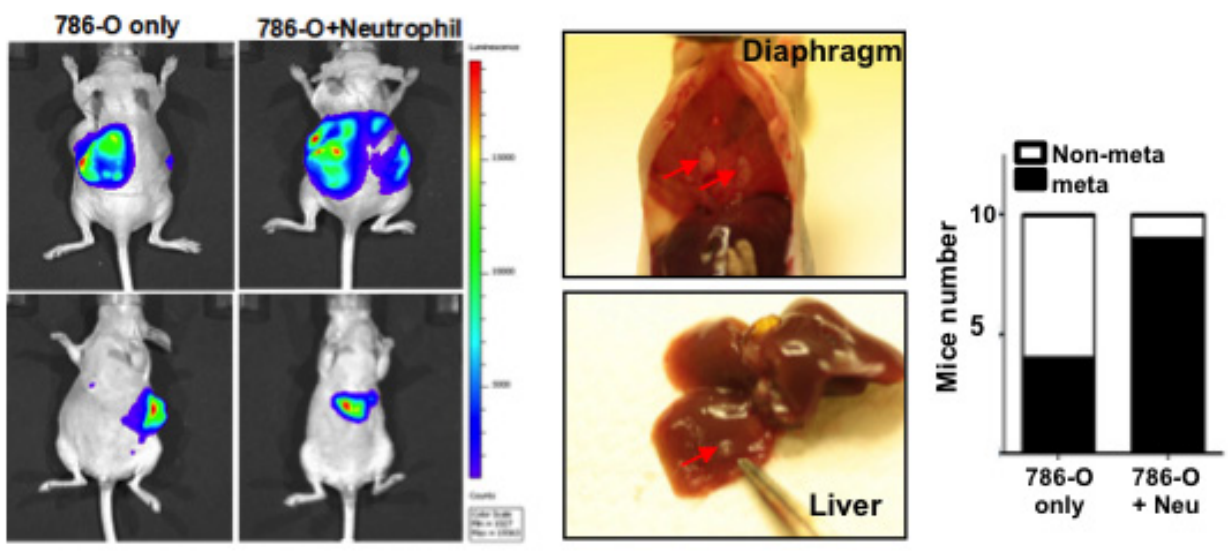

C.E.

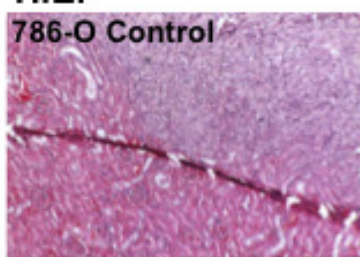

VEGFa

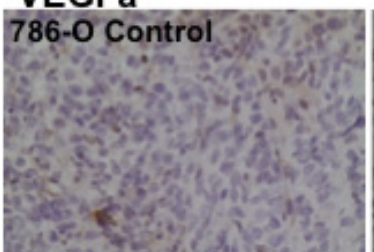

$786-0+$ Neu $(9: 1)$
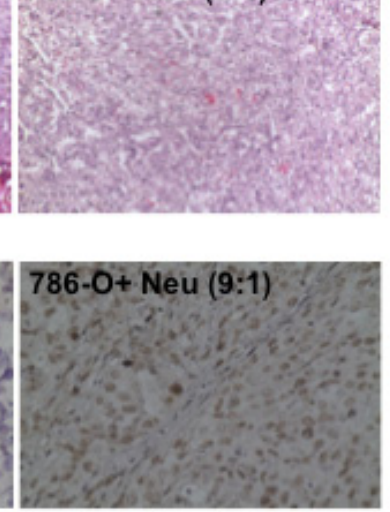

\section{ER $\beta$}

786-0 Control

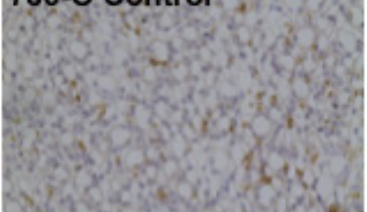

\section{HIF $2 \alpha$}

786-0 Control
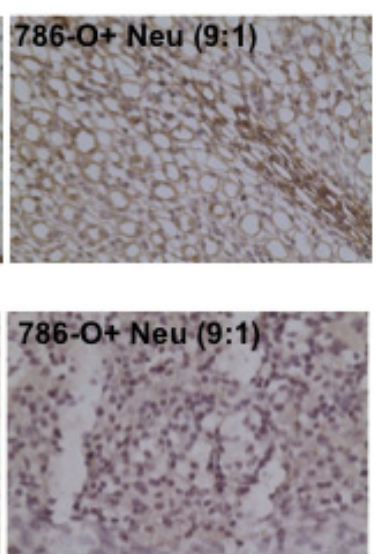
D

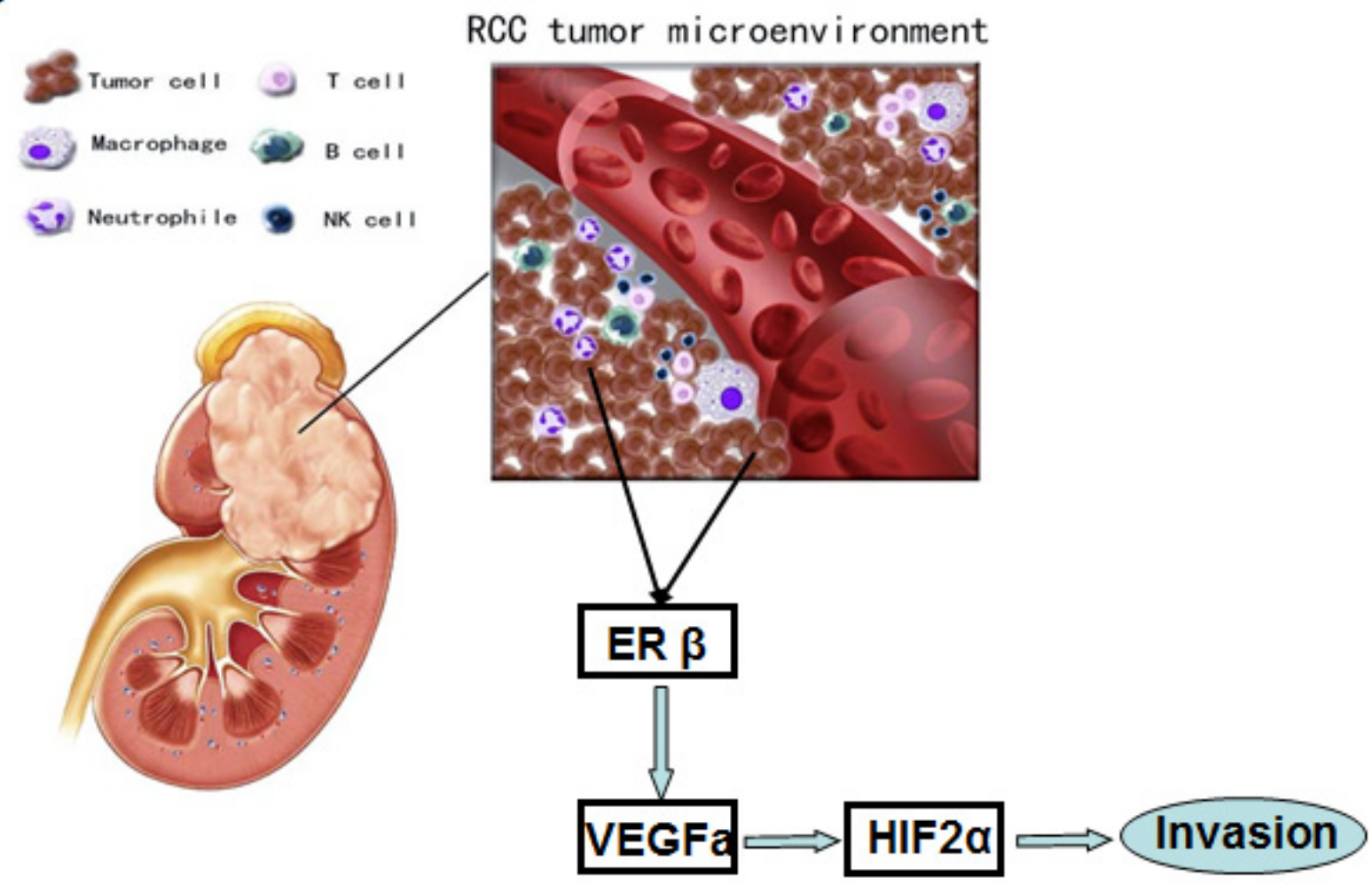

Figure 6: Tumor associated neutrophils could promote RCC invasion in orthotopically implanted RCC model. 786$\mathrm{O}$ cells $\left(9 \times 10^{5}\right)$ and HL-60N cells $\left(1 \times 10^{5}\right)$ were orthotopically co-implanted into the renal capsule of nude mice. After 6 weeks, the RCC growth and metastasis were evaluated. A. The 786-O cells co-injected with HL-60N cells showed a higher tumor growth rate. Tumor weights in each group were measured. B. Metastases were found in the diaphragm (middle panel, representative picture) of neutrophils co-implanted RCC tumors. RCC cells were stably transfected with luciferase cDNA in order to perform non-invasive in vivo imaging (IVIS), which was applied to monitor the RCC growth and metastasis. Mouse numbers with or without metastatic tumors of each group were quantitated (right panel, $n=10$ for each group). C. Histology analyses of RCC tumors formed in nude mice. IHC and H\&E results indicated that HL-60N co-implanted RCC tumors are positively correlated with higher ER $\beta$ (upper right panel), VEGFa (lower left panel) and HIF $2 \alpha$ (lower right panel). Anti-ER $\beta$ antibody can detect predominate nuclei staining signals of ER $\beta$ in RCC tumors. D. Summary of mechanisms and regulatory pathways of neutrophils-promoted RCC progression. RCC cells can better recruit neutrophil infiltration. RCC cells and neutrophils interact with each other in the RCC tumor microenvironment. The infiltrated neutrophils can function via increasing ER $\beta$ to up-regulate VEGFa and HIF2 $\alpha$ signaling and lead to an increased RCC invasion.

to be associated with poor prognosis in primary breast cancer [22] and RCC [23]. Consistently, studies, have shown neutrophil depletion experiments led to an inhibited tumor growth [24], limited metastasis numbers [25] and reduced endothelial recruitment to the tumors [26]. Our results confirm the rather anti-tumor role of neutrophils as we found significantly higher ratios of these cells in dissociated tumor cell suspension from advanced RCC patients with T3-T4 and metastatic disease. In our study, results showed that RCC patients have higher proportions of neutrophils in tumor samples than in adjacent normal tissues. Higher percentages of neutrophil cells were found in the tumor tissues in the higher grade tumor tissues from RCC patients (Figure 1). These findings may reflect the possibility of cancer-induced systemic as well as local immunosuppression, which both seem to be the early event in the course of the disease.

In this study, we sought to determine the role of neutrophils on RCC progression and whether ER $\beta$ plays differential functions between immune cells and RCC cells. The crosstalk between immune cells and tumor cells that leads to phenotypic alterations in tumor biology has been broadly termed immunosculpting or immunoediting [27]. In this study, we sought to determine the role of neutrophils on RCC progression and whether ER $\beta /$ VEGFa/HIF2 $\alpha$ play important roles for the interactions between immune cells and RCC cells. In addition, we found that ER $\beta$ can promote RCC progression via TGF- $\beta /$ SMAD3 pathway (Song and Yeh, et al, 2015 paper submitted). Furthermore, a prior study in prostate cancer supportively showed that ligand-bound ER $\beta$ promotes the epithelial-mesenchymal transition via the VEGF pathway [28].

The VEGF pathway is an important regulator of angiogenesis [29]. Activation of this pathway triggers a network of signaling processes that promote endothelial cell growth, migration, and survival from preexisting vascular beds. The VEGF/VEGF-receptor axis plays 
an important role in the mobilization of endothelial progenitor cells from the bone marrow to distant sites of neovascularization. The well-established role of VEGF in promoting tumor angiogenesis and growth has led to the development of various biologic agents that target this pathway [29, 30]. RCC may be used as a model for the development of effective antiangiogenic therapies. It is well known that the estrogen receptors are nuclear proteins and several reports have shown the dominant nuclear staining $(>95 \%)$ of ER $\beta$. Recently, there was a report by $\mathrm{Yu} \mathrm{CP}$ et al. showing $\mathrm{ER} \beta$ expression is reduced in higher grade RCC and may play an inhibiting role for RCC development [31]. The reasons behind the different conclusions regarding the ER $\beta$ roles in $\mathrm{RCC}$ progression remain unclear. We obtained RCC cells from the ATCC bank and used those cells within 30 passages for data collection. There have been concerns regarding the histology of the ER $\beta$ signal detected by Yu CP et al. using rabbit anti-ER $\beta$ (Epitomics), which did not show a dominant nuclear staining [31]. Also, the specificity of this rabbit anti-ER $\beta$ (Epitomics) is not well characterized for ER $\beta$ IHC staining in the nuclear receptor field.

Neutrophils are thought to play an important role in normal physiological angiogenesis. During the menstrual cycle, angiogenesis occurs in order to support the proliferation and growth of the endometrial tissue. The source of the potent pro-angiogenic factor VEGFa in these tissues was found to be from neutrophils. In fact, neutrophils expressing VEGFa could be found in the microvessels of the endometrium during the proliferative stage of the cycle when the endometrium can quadruple in thickness [32], which suggest the potential impacts of neutrophil secreted VEGFa in tumor progression. In the present study, our data showed that ER $\beta$ increased VEGFa activity and promoted angiogenesis-related gene expressions. The detailed mechanisms by which ER $\beta$ regulates VEGFa and HIF- $2 \alpha$ could be further delineated in future studies.

\section{MATERIALS AND METHODS}

\section{Human samples and IHC staining}

To investigate the expression of CD66b + neutrophils in human RCC tissues, we collected malignant tissue specimens, as well as 15 adjacent normal tissues, from 60 clear cell RCC patients who had undergone partial or radical nephrectomy for primary RCC, at the Department of Urology, the First Affiliated Hospital of Medicine School, Xi'an Jiaotong University, between 2002 and 2012. All tumor tissues were evaluated according to the 2009 edition of the TNM system and nuclear grading was performed according to WHO guidelines.

Formalin-fixed, paraffin-embedded samples were cut to a thickness of $5 \mu \mathrm{m}$. Each tissue section was deparaffinized and rehydrated with graded ethanol. For antigen retrieval, the slides were put in $1 \mathrm{mM}$ EDTA solution ( $\mathrm{pH} 8.0$ ) and boiled in a microwave oven for 15 min. Endogenous peroxidase activity was blocked with a $0.3 \%$ hydrogen peroxide solution for $10 \mathrm{~min}$ at room temperature. After rinsing with $\mathrm{PBS}$, slides were incubated overnight at $4^{\circ} \mathrm{C}$ with respective primary antibodies which include mouse anti-human CD66b monoclonal antibody (ThermoFisher; dilution 1:50). After three washes in PBS, sections were incubated with biotinylated anti-mouse secondary antibody for $30 \mathrm{~min}$ at room temperature. Immunostaining was performed using the Envision System with diaminobenzidine (DakoCytomation, Glostrup, Denmark). Finally, the signal was developed with 3,3'-diaminobenzidine tetrahydrochloride (DAB), and all of the slides were counterstained with hematoxylin. Data were obtained by manually counting positively stained cells in five separate areas of intratumoral regions under $400 \times$ high-power magnification. Densities were determined by computing the mean number of positively stained cells per high power microscopic field [33, 34].

\section{Cell culture and stable cell lines}

The human RCC cell lines 786-O (with high endogenous ER $\beta$ level), and A498 (with low endogenous $\mathrm{ER} \beta$ ) were purchased from ATCC and grown in DMEM media containing $1 \%$ antibiotics and 10\% fetal bovine serum (FBS) and maintained in 10\% heat-inactivated FBS RPMI media with $1 \%$ Pen/Strep. Normal human kidney proximal tubular cell lines, HKC-2/HKC-8 (ER $\beta$ positive) were kindly provided by Dr. Syed Khundmiri from University of Louisville (Louisville, KY), and maintained in Dulbucco's Minimum Essential Medium (DMEM) (Invitrogen, Carlsbad, CA) with 10\% FBS. The ER $\beta$ knockdown of 786-O and ER $\beta$ overexpressing A498 cells were established by lentiviral transduction of siRNA $\operatorname{ER} \beta$ or $\operatorname{ER} \beta$ cDNA, respectively.

\section{Lentiviral expression plasmid construction and virus production}

ER $\beta$ (PLKO.1-puro-shER $\beta$ ) was constructed with target sequence 5'-GCGAGTAACAAGGGCATGGAA-3' according to Addgene's pLKO.1 protocol. Lentiviral particles were generated by calcium phosphate transfection of lentiviral expressing, packaging and envelop plasmids into HEK 293 cells. Lentiviral particles were collected to infect target cells according to previous reports [35].

The 786-O and A498 cell lines were stimulated with $1.25 \%$ DMSO for 2 weeks to be differentiated into neutrophils as HL-60N. All cell lines were cultured in a $5 \%(\mathrm{v} / \mathrm{v}) \mathrm{CO} 2$ humidified incubator at $37^{\circ} \mathrm{C}$. 


\section{Cell migration assay}

The CM from RCC cells and normal human kidney proximal tubular cell lines, HKC-2 and HKC- 8 , at $1 \times 10^{5}$ were plated into the lower chambers of the transwells with $5 \mu \mathrm{m}$ pore polycarbonate membrane inserts. $1 \times 10^{5}$ HL-60N cells were plated onto the upper chambers. After $8 \mathrm{hrs}$, the cells migrated into the lower chambers were collected and counted by the Bio-Rad TC10 automatic cell counter. Each data point was performed in triplicate and the experiments were independently repeated twice.

The migration capability of RCC cells was determined using the transwell assay. RCC cells were cocultured with HL-60N for 7 days, then trypsinized and seeded with serum-free DMEM into the upper chambers at $5 \times 10^{4}$ cells/well, the bottom chambers contained DMEM with $20 \%$ FBS, and incubated for $24 \mathrm{hr}$. The migrated RCC cells attached to the lower surface of the membrane were fixed by $4 \%$ paraformaldehyde and stained with $1 \%$ toluidine blue. Cell numbers were counted in five randomly chosen microscopic fields per membrane.

\section{Invasion assay}

For in vitro invasion assays [36], the upper chambers of the transwells $(8 \mu \mathrm{m}$ pore size) were pre-coated with the growth factor-reduced matrigel (matrigel: serum free RPMI $=1: 4)$ (BD Biosciences). Before invasion assays. RCC cells were co-cultured with HL-60N for 72 hrs in 6-well transwell plates $\left(0.4 \mu \mathrm{m}\right.$ pore size). $1 \times 10^{4}$ of HL-60N cells were plated onto the upper chambers and $1 \times 10^{5} \mathrm{RCC}$ cells were plated into the lower chambers. The conditioned media $(\mathrm{CM})$ were collected, diluted with 10\% FBS DMEM media at 1:1 ratio, added into the lower chambers, and the parental RCC cells $\left(1 \times 10^{5}\right)$ with or without indicated treatment were plated onto upper chambers. After $24 \mathrm{hrs}$ of incubation, the cells in the upper chamber were removed. The insert membranes were fixed in ice cold $75 \%$ alcohol, stained with crystal violet, and the positively stained cells were counted. The invaded RCC cell numbers were averaged from counting numbers of five random fields. Each data point was run in triplicate and each set of experiment was performed in triplicate.

\section{Quantitative PCR}

Total RNA was extracted from each cell line using Trizol (Invitrogen). Reverse transcription was performed using the iScript reverse transcription kit (Bio-Rad). Quantitative real-time PCR (qRT-PCR) was conducted using a Bio-Rad CFX96 system with SYBR green to determine the levels of mRNA expression of listed genes. Expression levels were normalized to the expression of GAPDH mRNA.

\section{Western blot assay}

Cells were washed twice in PBS and lysed with RIPA buffer containing 1\% protease inhibitors (Amresco, Cochran, USA). Protein concentration in the cell lystate solution was determined by BCA protein assay (Amresco, Cochran, USA). Each cell lystate was mixed with $5 \times$ SDSPAGE loading buffer (Amresco). Equivalent protein quantities were loaded to $7 \%-15 \%$ SDS-polyacrylamide gels (Bio-Rad). Proteins were electotransferred to PVDF membranes (Millipore, Atlanta GA, USA) that were blocked in Tris-buffered saline plus $0.05 \%$ Tween-20 (TBS-T) containing 5\% non-fat dried milk for $1 \mathrm{hr}$. The membranes were washed in TBS-T and incubated with each primary monoclonal antibody overnight at $4^{\circ} \mathrm{C}$ [37]. The following primary antibodies were used: Rabbit anti-ER $\beta$ polyclonal antibody (GTX 110607, GeneTex), rabbit anti-VEGF polyclonal antibody (Abcam ab46154, $1 \mu \mathrm{g} / \mathrm{ml})$ and mouse anti-HIF $2 \alpha$ monoclonal antibody (Abcam ab8365, 1:200 diluted) and mouse anti-GAPDH monoclonal antibody (Santa Cruz) were used at 1:1000 dilution. The immuno-positive bands were visualized with an ECL chemiluminescent detection system (Thermo Scientific), and the images were transferred to the Bio-rad imaging system. All analyses were performed at least in duplicate.

\section{Rapamycin treatment on neutrophil infiltration toward RCC cells and neutrophils-increased RCC invasion}

786-O (or HK2 cells) were seeded in 6-cm cell culture dishes $\left(1 \times 10^{5} / \mathrm{dish}\right)$. After $24 \mathrm{hrs}$, media were refreshed and mock control or rapamycin $(10 \mathrm{ng} / \mathrm{ml})$ was added. After $48 \mathrm{hrs}$, CMs were collected for the following neutrophil recruitment assays. The CM collected from HK2 (or 786-O cells) with/without rapamycin treatment were passed through $0.45 \mu \mathrm{M}$ filters. CMs were then added in the bottom wells of 24-well transwells. Neutrophils were seeded into the upper wells of transwells with serum free media $\left(1 \times 10^{5}\right.$ in $150 \mu \mathrm{l}$ media/well, pore size: $\left.5 \mu \mathrm{m}\right)$. After 3 hrs of incubation, infiltrated neutrophils in the media of the bottom wells were collected and counted.

For in vitro invasion assays, the upper chambers of the transwells (Corning; pore size: $8 \mu \mathrm{m}$ ) were precoated with matrigel containing reduced-growth factors (1:4 serum free RPMI media) (BD Biosciences, Sparks, $\mathrm{MD})$. Before the invasion assays, RCC cells were cultured alone or co-cultured with HL-60N for $48 \mathrm{hrs}$ in 6-well transwell plates (Corning; pore size: $0.4 \mu \mathrm{m}$ ) with/without rapamycin $(10 \mathrm{ng} / \mathrm{ml})$ treatment. $1 \times 10^{5}$ of HL-60N cells were plated onto the upper chambers and $1 \times 10^{6} \mathrm{RCC}$ cells were seeded into the lower chambers. We tested 5 types of rapamycin treatments, (i) HL-60N cells were treated with rapamycin for $24 \mathrm{hrs}$, then cells 
were rinsed with new media twice to wash out the excess rapamycin, then co-cultured with 786-O; (ii) HL-60N and 786-O cells were both treated with rapamycin for $24 \mathrm{hrs,}$ then rapamycin was washed out, and then cells remained co-cultured together; (iii) only 786-O cells were treated with rapamycin before co-culture, and (iv) HL-60N and 786-O cells were co-cultured together in the presence of rapamycin for $48 \mathrm{hrs}$. The CM were collected, diluted with $10 \%$ FBS DMEM media at the ratio of $1: 1$, plated into the lower chambers, and the parental RCC cells $\left(1 \times 10^{5}\right)$ without treatment were plated onto upper chambers of transwell plates. After $18 \mathrm{hrs}$ incubation, the non-invaded cells in the upper chambers were removed. The insert membranes were fixed in ice cold $75 \%$ alcohol, stained with crystal violet, and the positively stained cells attached to the bottom of the membranes were counted under the microscope. The numbers of invaded cells were averaged from counting of five random fields. Each sample was run in triplicate and in at least 3 independent experiments.

\section{In vivo metastasis studies}

Female nude mice (7-8 weeks old) were purchased from NCI. Group 1 mice were implanted with $1 \times 10^{6} 786-\mathrm{O}$ cells (mixed with Matrigel, 1:1v/v) and Group 2 mice were co-implanted with $1 \times 10^{6} 786-\mathrm{O}$ cells and $1 \times 10^{5}$ HL-60N cells into renal capsule, ( $n=5 /$ each group). At the end of experiments, the tumors grown in the renal capsule were harvested, measured, and fixed for further histopathological analysis. Metastatic foci were counted and collected [36].

\section{IHC for animal model}

The mouse RCC tumor samples were fixed in 4\% neutral buffered para-formaldehyde, and embedded in paraffin. The primary antibodies of the mouse antihuman CD66b monoclonal antibody (Thermo Fisher), mouse monoclonal antibody to ER $\beta$ (Abcam 14C8 1:50), rabbit anti-VEGF polyclonal antibody (Abcam ab46154, 1:1000) and mouse anti-HIF-2 $\alpha$ monoclonal antibody (Abcam ab8365, 1:1500 diluted) were used for staining. The primary antibody was recognized by the biotinylated secondary antibody (Vector), and visualized by VECTASTAIN ABC peroxidase system and peroxidase substrate DAB kit (Vector) [38].

\section{Statistical Analysis}

Data are presented as mean $\pm \mathrm{SD}$ from at least 3 independent experiments. Statistical analyses involved paired t-test with SPSS 17.0 (SPSS Inc., Chicago, IL). For in vivo studies, measurements of tumor metastasis among the three groups were analyzed through one-way
ANOVA coupled with the Newman-Keuls test. $P<0.05$ was considered statistically significant.

\section{ACKNOWLEDGMENTS}

We thank Dr. Chawnshang Chang for helpful discussions and Karen Wolf for assistance on manuscript preparation. Some parts of Figure 6D cartoon were modified from images presented on http:/www.openneighborhood.org/great-blood-flow-is-important-in-manyways/, and http://kidney-pain.org/kidney-cancer/

\section{REFERENCES}

1. Ferlay J, Shin HR, Bray F, Forman D, Mathers C and Parkin DM. Estimates of worldwide burden of cancer in 2008: GLOBOCAN 2008. International Journal of Cancer. 2010; 127:2893-2917.

2. Nelson EC, Evans CP and Lara Jr PN. Renal cell carcinoma: current status and emerging therapies. Cancer Treatment Reviews. 2007; 33:299-313.

3. Ko JS, Zea AH, Rini BI, Ireland JL, Elson P, Cohen P, Golshayan A, Rayman PA, Wood L and Garcia J. Sunitinib mediates reversal of myeloid-derived suppressor cell accumulation in renal cell carcinoma patients. Clinical Cancer Research. 2009; 15:2148-2157.

4. Minárik I, Lašt'ovička J, Budinský V, Kayserová J, Špíšek R, Jarolím L, Fialová A, Babjuk M and Bartůn̆ková J. Regulatory $\mathrm{T}$ cells, dendritic cells and neutrophils in patients with renal cell carcinoma. Immunology letters. 2013; 152:144-150.

5. Finn OJ. Cancer immunology. New England Journal of Medicine. 2008; 358:2704-2715.

6. Pichler M, Hutterer G, Stoeckigt C, Chromecki T, Stojakovic T, Golbeck S, Eberhard K, Gerger A, Mannweiler S and Pummer K. Validation of the pretreatment neutrophil-lymphocyte ratio as a prognostic factor in a large European cohort of renal cell carcinoma patients. British journal of cancer. 2013; 108:901-907.

7. Tazzyman S, Lewis CE and Murdoch C. Neutrophils: key mediators of tumour angiogenesis. International journal of experimental pathology. 2009; 90:222-231.

8. Fridlender ZG, Sun J, Mishalian I, Singhal S, Cheng G, Kapoor V, Horng W, Fridlender G, Bayuh R and Worthen GS. Transcriptomic analysis comparing tumor-associated neutrophils with granulocytic myeloid-derived suppressor cells and normal neutrophils. PLoS One. 2012; 7:e31524.

9. Gregory $\mathrm{AD}$ and Houghton AM. Tumor-associated neutrophils: new targets for cancer therapy. Cancer research. 2011; 71:2411-2416.

10. Donskov F. Immunomonitoring and prognostic relevance of neutrophils in clinical trials. Seminars in cancer biology: Elsevier. 2013; pp. 200-207.

11. Henderson B, Ross R and Bernstein L. Estrogens as a 
cause of human cancer: the Richard and Hinda Rosenthal Foundation award lecture. Cancer Research. 1988; 48:246253.

12. Fox EM, Davis RJ and Shupnik MA. ER $\beta$ in breast canceronlooker, passive player, or active protector? Steroids. 2008; 73:1039-1051.

13. Hsu I, Vitkus S, Da J and Yeh S. Role of oestrogen receptors in bladder cancer development. Nature Review Urology. 2013;10:317-326.

14. Luan FL, Ding R, Sharma VK, Chon WJ, Lagman M and Suthanthiran M. Rapamycin is an effective inhibitor of human renal cancer metastasis1. Kidney International. 2003; 63:917-926.

15. Wu MY, Fu J, Xu J, O'Malley BW and Wu RC. Steroid receptor coactivator 3 regulates autophagy in breast cancer cells through macrophage migration inhibitory factor. Cell Research. 2012; 22:1003-1021.

16. Knoechel B, Roderick JE, Williamson KE, Zhu J, Lohr JG, Cotton MJ, Gillespie SM, Fernandez D, Ku M, Wang H, Piccioni F, Silver SJ, Jain M, Pearson D, Kluk MJ, Ott CJ, et al. An epigenetic mechanism of resistance to targeted therapy in $\mathrm{T}$ cell acute lymphoblastic leukemia. Nature Genetics. 2014; 46:364-370.

17. Mulholland DJ, Tran LM, Li Y, Cai H, Morim A, Wang S, Plaisier S, Garraway IP, Huang J, Graeber TG and Wu $\mathrm{H}$. Cell autonomous role of PTEN in regulating castrationresistant prostate cancer growth. Cancer Cell. 2011; 19:792804.

18. Iida $\mathrm{T}$, Iwahashi $\mathrm{M}$, Katsuda $\mathrm{M}$, Ishida $\mathrm{K}$, Nakamori M, Nakamura M, Naka T, Ojima T, Ueda K, Hayata K, Nakamura Y and Yamaue H. Tumor-infiltrating CD4+ Th17 cells produce IL-17 in tumor microenvironment and promote tumor progression in human gastric cancer. Oncology Reports. 2011; 25:1271-1277.

19. Khayyata S, Basturk O and Adsay NV. Invasive micropapillary carcinomas of the ampullo-pancreatobiliary region and their association with tumor-infiltrating neutrophils. Modern pathology : an official journal of the United States and Canadian Academy of Pathology, Inc. 2005; 18:1504-1511.

20. Queen MM, Ryan RE, Holzer RG, Keller-Peck CR and Jorcyk CL. Breast cancer cells stimulate neutrophils to produce oncostatin $\mathrm{M}$ : potential implications for tumor progression. Cancer Research. 2005; 65:8896-8904.

21. Ardi VC, Kupriyanova TA, Deryugina EI and Quigley JP. Human neutrophils uniquely release TIMP-free MMP-9 to provide a potent catalytic stimulator of angiogenesis. Proceedings of the National Academy of Sciences. 2007; 104:20262-20267.

22. Yamashita J-i, Ogawa M and Shirakusa T. Free-form neutrophil elastase is an independent marker predicting recurrence in primary breast cancer. Journal of Leukocyte Biology. 1995; 57:375-378.

23. Jensen HK, Donskov F, Marcussen N, Nordsmark M,
Lundbeck F and von der Maase H. Presence of intratumoral neutrophils is an independent prognostic factor in localized renal cell carcinoma. Journal of Clinical Oncology. 2009; 27:4709-4717.

24. Pekarek LA, Starr BA, Toledano AY and Schreiber H. Inhibition of tumor growth by elimination of granulocytes. The Journal of Experimental Medicine. 1995; 181:435-440.

25. Tazawa H, Okada F, Kobayashi T, Tada M, Mori Y, Une Y, Sendo F, Kobayashi M and Hosokawa M. Infiltration of neutrophils is required for acquisition of metastatic phenotype of benign murine fibrosarcoma cells: implication of inflammation-associated carcinogenesis and tumor progression. The American Journal of Pathology. 2003; 163:2221-2232.

26. Sparmann A and Bar-Sagi D. Ras-induced interleukin-8 expression plays a critical role in tumor growth and angiogenesis. Cancer cell. 2004; 6(5):447-458.

27. Reiman JM, Kmieciak M, Manjili MH and Knutson KL. Tumor immunoediting and immunosculpting pathways to cancer progression. Seminars in Cancer Biology: Elsevier. 2007; pp. 275-287.

28. Leung Y-K, Lam H-M, Wu S, Song D, Levin L, Cheng $\mathrm{L}, \mathrm{Wu} \mathrm{C}-\mathrm{L}$ and Ho S-M. Estrogen receptor $\beta 2$ and $\beta 5$ are associated with poor prognosis in prostate cancer, and promote cancer cell migration and invasion. Endocrinerelated Cancer. 2010; 17:675-689.

29. Carmeliet P. Angiogenesis in life, disease and medicine. Nature. 2005; 438:932-936.

30. Choueiri TK, Bukowski RM and Rini BI. (2006). The current role of angiogenesis inhibitors in the treatment of renal cell carcinoma. Seminars in Oncology: Elsevier. 2006; pp. 596-606.

31. Yu CP, Ho JY, Huang YT, Cha TL, Sun GH, Yu DS, Chang FW, Chen SP and Hsu RJ. Estrogen inhibits renal cell carcinoma cell progression through estrogen receptor- $\beta$ activation. PLoS One. 2013;8:e56667.

32. Mueller MD, Lebovic DI, Garrett E and Taylor RN. Neutrophils infiltrating the endometrium express vascular endothelial growth factor: potential role in endometrial angiogenesis. Fertility and Sterility. 2000; 74:107-112.

33. Chen JG, Xia JC, Liang XT, Pan K, Wang W, Lv L, Zhao JJ, Wang QJ, Li YQ, Chen SP, He J, Huang LX, Ke ML, Chen YB, Ma HQ, Zeng ZW, et al. Intratumoral expression of IL-17 and its prognostic role in gastric adenocarcinoma patients. International Journal of Biological Sciences. 2011; 7:53-60.

34. Zhao JJ, Pan K, Wang W, Chen JG, Wu YH, Lv L, Li JJ, Chen YB, Wang DD, Pan QZ, Li XD and Xia JC. The prognostic value of tumor-infiltrating neutrophils in gastric adenocarcinoma after resection. PLoS One. 2012; 7:e33655.

35. Hsu I, Chuang KL, Slavin S, Da J, Lim WX, Pang ST, O'Brien JH and Yeh S. Suppression of ERbeta signaling via ERbeta knockout or antagonist protects against bladder cancer development. Carcinogenesis. 2014; 35(3):651-661. 
36. Slavin S, Yeh CR, Da J, Yu S, Miyamoto H, Messing EM, Guancial E and Yeh S. Estrogen receptor alpha in cancer-associated fibroblasts suppresses prostate cancer invasion via modulation of thrombospondin 2 and matrix metalloproteinase 3. Carcinogenesis. 2014; 35:1301-1309.

37. Chen M, Yeh CR, Chang HC, Vitkus S, Wen XQ, Bhowmick NA, Wolfe A and Yeh S. Loss of epithelial oestrogen receptor alpha inhibits oestrogen-stimulated prostate proliferation and squamous metaplasia via in vivo tissue selective knockout models. The Journal of Pathology. 2012; 226:17-27.

38. Hsu I, Yeh CR, Slavin S, Miyamoto H, Netto GJ, Tsai YC, Muyan M, Wu XR, Messing EM, Guancial EA and Yeh S. Estrogen receptor alpha prevents bladder cancer via INPP4B inhibited akt pathway in vitro and in vivo. Oncotarget. 2014; 5:7917-7935.

39. Prins GS, Birch L, Couse JF, Choi I, Katzenellenbogen $\mathrm{B}$ and Korach KS. Estrogen imprinting of the developing prostate gland is mediated through stromal ER $\alpha$ : Studies with $\alpha E R K O$ and $\beta E R K O$ mice. Cancer Research. 2001;61:6089-6097.

40. McPherson SJ, Hussain S, Balanathan P, Hedwards SL, Niranjan B, Grant M, Chandrasiri UP, Toivanen R, Wang Y, Taylor RA and Risbridger GP. Estrogen receptor- $\beta$ activated apoptosis in benign hyperplasia and cancer of the prostate is androgen independent and TNFalpha mediated. Proceedings of the National Academy of Sciences. 2010;107:3123-3128. 